Abstracta Iranica Abstracta Iranica

Revue bibliographique pour le domaine irano-aryen

Volume 26 | 2005

Comptes rendus des publications de 2003

Le rêve et ses interprétations en Islam. Postface de J. M. Hirt, Paris, Albin Michel, 2003, 311 p. [Sciences des religions]

Ève Feuillebois-Piérunek

(2) OpenEdition

Journals

Édition électronique

URL : http://journals.openedition.org/abstractairanica/2431

ISSN : 1961-960X

Éditeur :

CNRS (UMR 7528 Mondes iraniens et indiens), Éditions de l'IFRI

Édition imprimée

Date de publication : 15 mai 2005

ISSN : 0240-8910

Référence électronique

Ėve Feuillebois-Piérunek, « Le rêve et ses interprétations en Islam. Postface de J. M. Hirt, Paris, Albin

Michel, 2003, 311 p. [Sciences des religions] », Abstracta Iranica [En ligne], Volume 26 | 2005, document 305, mis en ligne le 07 décembre 2005, consulté le 25 septembre 2020. URL : http://

journals.openedition.org/abstractairanica/2431

Ce document a été généré automatiquement le 25 septembre 2020.

Tous droits réservés 


\title{
Le rêve et ses interprétations en Islam. Postface de J. M. Hirt, Paris, Albin Michel, 2003, 311 p. [Sciences des religions]
}

\author{
Ève Feuillebois-Piérunek
}

1 Cet excellent ouvrage, destiné à un public non spécialisé, est conçu comme une introduction à l'étude des rêves dans la culture musulmane. Avec l'achèvement de la Prophétie à la mort de Muhammad en 632, le rêve reste l'un des seuls moyens d'accès à l'Au-delà. C'est ce qui découle de l'enseignement du prophète et d'une certaine lecture $\mathrm{du}$ Coran. Le songe est donc la source d'une Révélation permanente. L'intérêt pour les rêves a commencé avec l'étude de ceux du prophète. On s'est efforcé de les répertorier selon leurs thèmes (vision de Dieu, des anges, des prophètes et des saints, ou au contraire de djinns ou de démons, rituels, mort et au-delà, parenté, société, corps, objets et actes de la vie quotidienne) et selon leur nature (rêves véridiques ou incohérents voire démoniaques). Des théologiens ont essayé de faire cadrer la réalité de ces rêves avec les lois religieuses: Ghazali s'est attaché à donner au rêve une interprétation métaphysique finalisée par l'expérience mystique; Ibn Khaldun, plus pragmatique, explique de façon pénétrante la nature et la portée des rêves.

2 En s'appuyant sur les grands textes de la littérature onirocritique musulmane (Ibn Sirin au

$7^{\mathrm{e}-8^{\mathrm{e}}}$ s., Ibn Qutayba au 9e s., Dinawari, Abu Sa'd al-Kharkushi, Abu Ali Dari, Ibn Shahin, Nabulsi à partir du $10^{\mathrm{e}}-11^{\mathrm{e}} \mathrm{s}$.), P. Lory met en lumière la remarquable homogénéité des diverses clefs des songes issues des traditions de l'Antiquité (Artémidore et la Bible) et de l'islam. Une attention particulière est accordée aux milieux soufis où le rêve est considéré comme un événement initiatique, une ouverture sur le Divin. Les expériences de Bastami, Junayd, Tirmidhi, Ruzbehan Baqli Shirazi et Ibn 'Arabi sont relatées. 
INDEX

Thèmes : 7. Islam

nompropre Ibn Khaldun, Ghazali, Bastami, Ruzbehan Baqli Shirazi, Ibn 'Arabi

\section{AUTEURS}

ÈVE FEUILLEBOIS-PIÉRUNEK

Sorbonne Nouvelle - Paris III 